\title{
Algunas noticias sobre una fábrica de vidrio de Venecia en San Martín de Valdeiglesias (1679-1689)
}

\author{
Justina Rodríguez Garcia *
}

En 1679, año en que se creó en España la Real y General Junta de Comercio, cuyo más importante cometido era el fomento de la industria ${ }^{1}$, llegó a la corte de Madrid, procedente de Flandes, el maestro vidriero Dieudonné Lambotte. Era hijo de Thiry o Thierry Lambotte que trabajó en Namur en la fabricación de espejos y vidrios planos para ventanas desde 1626 a 1657, con las acostumbradas concesiones reales que solían facilitarse en este tipo de actividades industriales. El 13 de octubre de 1643 Felipe IV le otorgó la renovación de un privilegio que venía disfrutando desde años atrás para continuar fabricando "vidrios planos de ventana" durante nueve años, teniendo que pagar a la Corona un canon anual de 100 libras. De esta manera Lambotte adquiría el monopolio de fabricación de sus productos en el condado de Namur, pues se daba la circunstancia

\footnotetext{
* Profesora de Historia Moderna. UNED.

1 La Junta de Comercio fue creada por Real Decreto de 29 de enero de 1679 por iniciativa del duque de Medinaceli y siendo primer ministro D. Juan José de Austria, para «restablecer y restaurar el comercio general de estos reinos». En la práctica, sus afanes se encaminaron fundamentalmente al fomento y desarrollo de la industria. Lope de los Ríos, del Consejo de Castilla, como presidente, Carlos Herrera Ramírez de Arellano, Francisco Centani y Josep de Veytia fueron los cuatro Ministros que componían la Junta a raíz de su fundación. Su primera y corta etapa concluyó en abril de 1680, pero en diciembre de 1682 se volvieron a reanudar sus sesiones: E. LARRUGa y BONETA, Historia de la Real y General Junta de Comercio, Moneda y Minas (Manuscrito de la Biblioteca del Ministerio de Hacienda). Madrid 1789, t. 2, fol. 2-3; P. Molas Ribalta, "La Junta General de Comercio y Moneda. La institución y los hombres", Cuadernos de Historia. Anexos de la Revista Hispania, n. ${ }^{\circ} \mathrm{IX}, 1978$, pp. 2-4.
} 
de estar en vigencia la prohibición de vender manufacturas extranjeras dentro de los Países Bajos.

En enero de 1650 obtuvo otra concesión real, extensiva a sus hijos, que estaba concebida en términos muy semejantes a la anterior: nueve años de duración y 110 libras de aportación anual a la Real Hacienda. Estando en plena actividad la fábrica y con resultados productivos muy satisfactorios, murió Thiry Lambotte en julio de 1657. Su viuda, Barbe de Tier, y sus tres hijos, Godofried, André y Dieudonné, continuaron la labor que su padre había llevado a tan buen término, pero con menor fortuna. Al concluir en 1659 el privilegio real, los hijos de T. Lambotte solicitaron una prórroga por otros nueve años que le fue concedida el 19 de julio de 1659, pero suprimía el monopolio al introducir una cláusula en la que se hacía constar que no se excluía la posibilidad de otorgar nuevas concesiones a otros maestros vidrieros. Estas circunstancias poco favorables a la factoría de los Lambotte se agravaron tras la Paz de los Pirineos acordada algunos meses después, al ser permitida la entrada de manufacturas extranjeras con precios altamente competitivos, especialmente las francesas. Este hecho y la instalación de otra nueva factoría de vidrios planos y espejos en Namur determinaron el cierre de la fábrica de los Lambotte en 1663. Seis años después volvió a estar en actividad, pero, a pesar de las paulatinas reducciones de su aportación al fisco, supervivió sólo unos años más, hasta su clausura definitiva en $1677^{2}$.

En el tiempo que transcurrió desde que el horno fue cerrado hasta el año 1679, Dieudonné Lambote tomó contacto en su país con el Duque de Villahermosa, a la sazón gobernador español en los Países Bajos, quien a instancias del rey Carlos II le propuso venir a España para establecer en Castilla, cerca de la corte, una fábrica de vidrio al estilo del de Venecia para poder satisfacer la gran demanda española de estos productos, atendidos especialmente con importaciones venecianas ${ }^{3}$.

${ }^{2}$ S. Bormans, "La fabrication du verre en table à Namur", Bulletin des Commissions Royales d'Art et d'Archéologie, $\mathrm{n}^{\circ} \mathrm{XIX}, 1880$, pp. 450-456.

${ }^{3}$ En Flandes se desarrolló a lo largo de los siglo XVI y XVII una importante industria del vidrio con una producción muy semejante a la de Venecia, cuyo objetivo era evitar la gran demanda interior de estas manufacturas, fenómeno paralelo al que experimentaron la mayor parte de los países europeos a lo largo de estas dos centurias. Vidrieros venecianos y de Altare (localidad de la Liguria) se establecieron en múltiples ciudades flamencas (Amberes, Lieja, Namur, Bruselas, etc.) y con el apoyo real dirigieron importantes factorías dedicadas fundamentalmente a manufacturar vidrio "a la façon de Venise». Muchos maestros flamencos aprendieron el arte de sus colegas italianos y llegaron a ser tan expertos en su oficio como ellos: Ambrosio de Mongarda, Gridolphi, etc... Toda esta brillante actividad en torno a 
Uno de los éxitos más notables de la Junta de Comercio fue precisamente conseguir traer a España artífices europeos que contribuyeran al fomento y renovación de la industria con sus técnicas y conocimiento del oficio. Con la colaboración de estos maestros pretendía la nueva institución abastecer nuestro mercado con una producción de calidad que ayudara a disminuir, en la medida de lo posible, el alto índice de importación que tanto venía afectando a la maltrecha economía española ${ }^{4}$.

Aunque muchos vidrieros venecianos y flamencos habian iniciado su éxodo a España en fechas anteriores ${ }^{5}$, a partir de 1679 se incrementará su número gracias a la labor de dicha institución ${ }^{6}$.

la industria del vidrio está muy documentada y ha sido estudiada por importantes especialistas: J. Houdor, Verreries à la façon de Venise. La fabrication flamande d'aprés des documents inédits. París 1873; H. SchueRmans, "Verres Façon de Venise fabriqués aux Pay-Bas", Bulletin des Commissions Royales d'Art et d'Archéologie: varios números correspondientes a los años 1880-1889. Pese a su antigüedad, estos trabajos aportan un bagaje documental de enorme interés, aunque estén necesitados de una revisión. En España esta moda del vidrio de Venecia arraigó profundamente, llegando a ser indispensable la presencia de estos cotizados objetos en los ajuares reales y de las más destacadas familias de la nobleza, como se pone de manifiesto en los inventarios de bienes de los siglos XVI y XVII y a través de la correspondencia de los embajadores españoles en Venecia con la corte de Madrid.

En tiempo de Carlos II la Junta de Comercio fomentó en las provincias de Flandes el restablecimiento de la fabricación de determinados productos que se habían manufacturado alli tradicionalmente y que se estaban dispersando fuera de sus fronteras, concediendo exenciones fiscales para su exportación y en la entrada de materias primas que se utilizaban en la fabricación de los mismos (Ordenanza de 28 de abril de 1679): E. LARRUGA $Y$ BOnETA, Historia de la Junta de Comercio..., t. III, fol. 9.

" La Junta de Medios y la Junta de Comercio veian la necesidad de reducir el consumo interior de mercaderias extranjeras, porque de esta forma se daba salida a las propias, pero ello planteaba el problema de la incapacidad de las fábricas españolas para abastecer las necesidades del mercado interior y, sobre todo, del de América. Por esta razón no se llegó a prohibir la entrada de manufacturas, pero se intentó paliar este inconveniente trayendo artesanos extranjeros que dieran un mayor impulso a la industria del país: $E$. LARRUGA $Y$ BONETA, Historia de la Junta de Comercio..., t. I, fol. 50.

5 Un ejemplo muy ilustrativo es el del vidriero veneciano Domingo Barovier que estableció en El Escorial una pequeña factoría con el apoyo real en 1607: J. Rodriguez Garcia, «Domingo Barovier, vidriero veneciano en España (1605-1608)», Espacio, tiempo y forma, Homenaje al Prof. Antonio de Béthencourt y Massieu, n. ${ }^{\circ} 4 a, 1988$, p. 467-500. Otros muchos artistas del vidrio vinieron a España a lo largo del siglo XVII, especialmente durante la segunda mitad de la centuria, y se establecieron en su mayoría en los entornos de la corte de Madrid. Muy expresiva al respecto es la carta del Marqués de Villagarcia (de 11 de diciembre de 1677), embajador español en Venecia, en la que se hace eco de la petición de Jerónimo de Eguía de gestionar la venida a España de un maestro vidriero veneciano:

«Señor mío: En carta del 10 del caydo, se sirve V.S. de decirme que en la consideración de las raçones que se motiven en la çitada, ha tenido por bien $\mathrm{S}$. Magestad de mandarme que dispongan luego el embiar de aquí un oficial de los más 
Las primeras noticias relativas a la fábrica de vidrios de Dieudonné Lambotte en tierras de Castilla, concretamente en la villa de San Martín de Valdeiglesias, de la que E. Larruga deja constancia en sus Memorias... ${ }^{7}$, corresponden a la llegada del vidriero flamenco a Madrid en enero de 1679. En un memorial dirigido al monarca español hace una exposición de sus objetivos y presenta sus condiciones y compromisos ${ }^{8}$.

La fábrica que quiere establecer en Castilla, con el apoyo real, se encargará de fabricar "christal de roca y su fundición para hacer espejos de armar y de todos géneros; vidrios cristalinos para coches ${ }^{9}$, sillas de mano, ventanas y demás usos y para todo género de piezas que se labran según esta sciencia y arte, incluyéndose las piedras coloridas que se engastan...", lo que evitaría la importación de género procedente de Francia, Venecia y otros países, pues en España, sigue argumentando Lambotte, los materiales necesarios para la fabricación del vidrio son de excelente calidad, mejores que los que se utilizan en otras partes. Al fabricarse el vidrio de las cualidades mencionadas, evitando los costes

consumados y áviles que haya en estas fábricas de bidrios, assí en el modo de hacer las masas y dar temples, como en la diversidad de hechuras para los fines que en su carta de V.S. se me previenen, y quedando en inteligencia dello, diré a V.S. que tengo por arduo el sacar de aquí oficial de los requisitos mencionados y vencer, aunque se obre con toda maña y recato, los incombenientes que se ofrecen, si bien no desconfío de que los pueda superar el interés; pero siendo esta negociación de mucha costa, porque dicho oficial querrá benderse vien, como lo han hecho otros que se han llevado a París, y no se contentará con lo necesario para el viaje haviendo de dejar su domicilio, trato y familia, si la tuviere, pasando a parte tan remota...".

AHN, Estado, Libro 733, 11 de diciembre de 1677.

- La Junta de Comercio ejerció sus funciones solicitando de los embajadores españoles en las cortes aliadas y amigas información sobre el comercio y las manufacturas de sus respectivos países "con el fin de imitar su industria y atajar las ganancias que con tanto exceso disfrutaban en nuestros dominios»: E. LARRUGA $\gamma$ BONETA, Historia de la Junta de Comercio..., t. I, fol. 5 .

7 Dice así el texto de Larruga:

«En el reinado del Señor Carlos II, y en 1680, se estableció en la villa de San Martín de Valdeiglesias una fábrica de cristales como los de Venecia. Se hizo el horno y salieron algunas porciones de cristales huecos. Mientras vivió su Director Diodonet Lambot fue bien esta manufactura...".

E. LaRRuga y Boneta, Memorias politicas y económicas sobre los frutos, comercio, fábricas y minas de España. Madrid 1791-1792, t. XVI, p. 222-223.

8 AHN. Consejos, Leg. 13.215, 10 de enero de 1679.

9 La novedad de los cristales en los coches fue introducida en España hacia 1629 por Medina de las Torres, al regreso de su virreinato de Nápoles: Maura, Duque de y $A$. AMEZUA, Fantasias y realidades del viaje a Madrid de la Condesa d'Aulnay. Madrid 1943, p. 136. 
de aduanas, fletes, portes, etc., se obtendrían estos productos a la mitad del precio que los traídos de fuera ${ }^{10}$.

Después de ser sometido a la prueba de experimentar su arte en presencia del rey y poner de manifiesto que sus productos tenían una calidad y transparencia mayor que los que se traían del extranjero, promete, para poder llevar a cabo su labor en tierras de Castilla, abandonar su patria y traer consigo casa y familia, así como veinticinco oficiales diestros en el oficio, que era el número necesario para hacer frente a las actividades del horno y enseñar su arte a los naturales del reino.

El privilegio real por diez años, que se ofreció a Dieudonné Lambotte habría de ajustarse a las condiciones propuestas por él al rey, que en síntesis eran las siguientes:

1. Que el lugar para establecer el horno fuera en las vecindades de la corte de Madrid y reuniera los requisitos necesarios para el suministro de los materiales indispensables para la elaboración del vidrio -barrilla, leña, salitre, etc.- ${ }^{11}$. La adquisición de dichos productos no debía presentar ningún tipo de dificultad una vez concertados los precios con sus suministradores.

2. Además de este lugar cercano a la corte, que sería el elegido para el establecimiento principal de la fábrica, pedía Lambotte poder abrir otros cen las ciudades, villas o lugares de los reynos de Castilla que

${ }^{10}$ Esta argumentación de Lambotte responde a la preocupación existente en España, a la que ya se ha hecho referencia, por la creciente importación de productos manufacturados procedentes del extranjero.

11 San Martín de Valdeiglesias está situada en zona de bosques con abundantes pinares y madera para las necesidades del establecimiento. También sabemos que había un arroyo cercano de donde se obtenía arcilla para la construcción de los hornos. Juan Danis, un maestro vidriero de Valdemaqueda, autor, juntamente con Francisco Herranz, de un tratado sobre vidrio y la técnica de hacer vidrieras (1676), dice al respecto:

«Para hazer el horno se deve buscar barro del que se tenga experiencia que no derrita al mucho fuego, como es el barro negro que sacan de un arroyo que llaman Tórtolas que está entre San Martín y Cadahalso, uno blanco que ay en Segovia, que mezclados hacen muy buena unión, echando dos de lo negro y uno de lo blanco; deste barro se hazen en esta tierra los morteros o crisoles en que se hunde el vidro y de él se hacen adobes para hacer la capilla del horno, y las piedras del caño se alimentan con este barro. Estas piedras se traen del cerro de Guisando...".

V. NIETO ALCAIDE, “El Tratado de la fábrica del vidro de Juan Danis y el "modo" de hacer vidrieras de Francisco Herranz", Archivo Español de Arte, n. ${ }^{\circ} 147,1967$, p. 288. 
juzgare conveniente, quedando a su elección el hacerlo por el tiempo de diez años".

3. Que ningún otro fabricante natural del reino ni de cualquier otro lugar pudiera manufacturar en tierras de Castilla, durante los diez años previstos en el privilegio, vidrio de los tipos que él se comprometía a elaborar, para lo cual pedía como garantía que se depositaran y custodiaran oportunamente unas muestras de cada uno de estos productos que él personalmente se encargaría de hacer, con el fin de evitar problemas futuros con otros maestros activos en el reino, y poder comprobar, llegado el caso, si se habían copiado. Asimismo, pedia que estos vidrieros depositaran también las muestras de sus manufacturas con el mismo objeto.

4. Que se prohibiera a los veinticinco oficiales que habrian de acompañarle desde Flandes trabajar en ningún otro horno y, en caso de infringir esta orden, se castigara oportunamente tanto a los oficiales como a los que los admitieran en sus fábricas ${ }^{12}$.

5. Que el salitre (la sílice), la sosa y la barrilla, así como los demás componentes necesarios en la fabricación del vidrio "cristalino" ${ }^{13}$ lo pudieran transportar libremente a los lugares en donde se establecieran sus fábricas "sin pagar derechos algunos de aduanas, portazgos, alcavalas, uncs por ciento, ni otro alguno de los que debieran pagar dichos materiales». En caso de que los suministradores de salitre quisieran aumentar

12 El alto número de oficiales que propone el vidriero flamenco es un claro exponente de la importancia del establecimiento y del considerable apoyo financiero que la Corona le ofrecía. Los hornos activos en Castilla, anteriores o coetáneos a éste, todos con el apoyo real, contaban con menos medios materiales y humanos.

"El «cristallo" o vidrio cristalino fue inventado en el siglo XV por el más célebre vidriero de Murano, Angelo Barovier. Esta calidad de vidrio, cuyas características más notables son una gran ligereza y transparencia, proporcionó, junto con otros descubrimientos técnicos de la época, fama universal a los hornos de la isla, y se exportó a lo largo de varias centurias por todo el mundo. El llamado “cristal» es otro tipo de vidrio en cuya composición hay una importante cantidad de plomo que proporciona a la mezcla una dureza y brillantez muy semejantes al cristal de roca. Fue un invento inglés de la segunda mitad del siglo XVII (G. Ravenscroft: 1632-1683). En el tratado del vidriero de Valdemaqueda J. Danis ( $v$. nota 11) se dice que el "vidrio christal» (con plomo) se hace en Francia, Flandes y otras partes "y oy en San Martín, y el que se ha labrado en Vista Vella de Aragón" (V. NIETO AlCAIDE, «El Tratado de la fábrica de vidro...», p. 287). Se refiere, sin lugar a dudas, a San Martín de Valdeiglesias, en donde ya se fabricaba vidrio de calidad cuatro años antes de que la fábrica de Lambotte se estableciera en esta localidad, según nos cuenta el vidriero castellano. 
abusivamente el precio al que se estaba vendiendo de forma habitual, proponía Lambotte que él mismo se encargaría de conseguir, preparar y disponer este material para abastecer sus hornos sin que se le pusiera ningún tipo de traba.

6. Seguidamente, planteaba la necesidad de que tanto él y su familia como los veinticinco oficiales que le acompañaban y las suyas, con enseres, ropas, instrumentos para los hornos, etc., quedaran exentos de pagar derechos de puertos y aduanas.

7. La venta de los productos que se manufacturaran en sus fábricas (tanto en la principal como en las otras) habría de hacerse durante los diez años libre de alcabala, unos por ciento y cualquier otro tipo de cargas fiscales, a excepción de las que salieran fuera de los reinos de Castilla y León que tendrían que hacer frente a los derechos de aduanas y puertos.

8. Ponía también la condición de no quedar sometidos a la jurisdicción ordinaria en los tribunales de Castilla ni él ni los que le acompañaban, sino gozar de un peculiar estatuto jurídico a estos efectos ${ }^{14}$.

Pedía asimismo que, al igual que en Flandes, se le eximiera de pagar durante los diez años que durase el privilegio «todas las cargas concejiles, repartimientos, cobranzas, aloxamientos, contribución de milicias y otras cualesquiera de esta calidad, sin que por estos despachos se les lleven derechos algunos».

9. Finalmente, exponía los gastos que la Corona tendría que asumir relativos al desplazamiento de él y de sus veinticinco oficiales con fami-

${ }^{14}$ Sobre este particular dice así el documento:

"Que para más seguro establecimiento de estas fábricas y ebitar embarazos y las molestias que suelen ocasionar con algunos pretextos los ministros inferiores de justicia, se a de servir $V$. Magestad de elegir un ministro de autoridad, el que $V$. Magestad fuere servido, para que privativamente conozca de todas las causas cibiles y criminales del dicho Diodonet Lambot, su casa, familia y oficiales, con inhibición a todos los consejos, chancillerías, audiencias y otros y qualesquiera Jueces y Justicias de estos Reynos y señaladamente los Alcaldes de Casa y Corte, Correxidor de esta Villa de Madrid y subtenientes, concediéndoseles esta gracia en la más amplia forma que estuviere hecho con otro qualquiera, y así mismo se le an de despachar, por la parte a donde tocare, Cédulas de preheminencias al dicho Lambot y a sus oficiales, a imitación de las que éstos goçan en los países de Flandes...". 
lias y enseres, así como la construcción del horno, molino y demás dependencias de la fábrica. La relación es la que sigue:

"Que respecto de la mucha costa que a de tener en hacer venir a los estados de Flandes su muger, familia y los veinte y cinco oficiales que se obliga a traer y sus familias y asimismo en el horno, molino y demás oficinas que se an de fabricar para la fundición y fábrica del bidro de cristal se a de servir $V$. Magestad de mandar se le libren y paguen en dinero de contado las cantidades siguientes:

Reales de a ocho

- Para el gasto de familia del suplicante que a de hacer su biaje por tierra y su ropa, muebles y instrumentos para el horno, ducientos doblones

- Para el gasto del biaje de los veinte y cinco oficiales y algunas aiudas de costa que es previo darles para alentarlos más por causa de que dejan su país y haver entre ellos muchos que son nobles, siete mil y quinientos reales de a ocho a razón de trescientos reales de a ocho a cada oficial

- Para fabricar el horno en la parte donde se a de establecer la vidreria, cien doblones, que es lo que se considera ten-

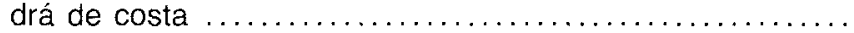

- Para hacer un cubierto en que a de estar dicho horno, ciento cinquenta doblones ..........................

- Para hacer un molino con su cubierto en que se an de moler las piedras y otros materiales, ciento cinquenta doblones ......................................

- Para hacer un cubierto grande en que se pone la leña y otras cosas dependientes de la fábrica, ochenta doblones

Que son diez mil ducientos y veinte reales de a ocho, de los dichos ocho mil y trescientos reales de a ocho que importan las dos primeras partidas que an de servir para el gasto y viaje de la familia del dicho Lambot y sus oficiales, se le an de entregar en letras para Flandes que importan los dichos ocho mil y trescientos reales de a ocho de efectiva paga en aquellos estados, o si se le pagaren en esta corte a de ser con más lo que montare su condución de aquí a Flandes según estuviere el cambio, al tiempo que se le entregare este dinero respecto de que le a de remitir a aquellos estados en letras para el cobro de dichos oficiales y para satisfacer los empeños que para ello se hicieren, y los mil novecientos y veinte reales de a ocho restantes que se componen de las partidas que son menester para la fábrica del horno, molino y otras oficinas se han de entregar también en contado y con la anticipación de tiempo que es preciso para poder tener hechas estas obras quando flegasen los oficiales y dar principio a la fábrica y en caso que el coste del dicho horno, molino y cubiertos importen menos que los mil novecientos y veinte reales de a ocho referidos, que es la cantidad que se 
supone importará el gasto de su fábrica, restituirá a la Real Hacienda el dicho Lambot lo que menos montare el coste, para lo qual podrá $V$. Magestad servirse de mandar imbiar personas inteligentes para que hagan la tasación quando esté acavada la obra» ${ }^{15}$.

Enumeradas todas estas condiciones, D. Lambotte se comprometía a establecer y asentar en Castilla la fábrica de vidrios cristalinos y mantener durante los diez años del privilegio a los veinticinco oficiales que habrian de venir; caso de que alguno de ellos falleciese, se obligaba a traer otro a su costa de la misma cualificación, a no ser que entre los naturales que trabajasen en la fábrica hubiera alguno con conocimientos suficientes para sustituirlo.

El 31 de mayo del mismo año 1679 Carlos II aprobaba la petición de Lambotte y la remitía a la Junta de Comercio y al Consejo para que pusieran en curso los trámites necesarios para su cumplimiento ${ }^{16}$, ordenando que se le concediera el privilegio en los términos planteados en el memorial del solicitante. Con la misma fecha se despachaba una cédula de paso para dejar entrar en España libres de derechos a los veinticinco oficiales de la fábrica con sus enseres.

El lugar que eligió Lambotte para el establecimiento de la factoría, como ya se ha indicado, fue San Martín de Valdeiglesias, en la actual provincia de Madrid, cercano a Cadalso de los Vidrios, uno de los centros de producción vidriera más notables de Castilla.

En 1680 la fábrica ya estaba en actividad, como se pone de manifiesto en la queja que los vecinos de San Martín de Valdeiglesias elevan al rey en febrero de este año a propósito de las pérdidas que están sufriendo los bosques de la villa por la tala continuada de pinos para el abastecimiento de combustible del horno del maestro flamenco, sin recibir a cambio ningún tipo de beneficios, "siendo así que otros hornos de menor calidad que a havido en ella an pagado cada año ochocientos reales por la corta de la leña que cortaran para el horno, como subcede en Cadahalso y en otras partes donde hay semejantes fábricas de bidro". En compensación por este continuado gasto, ya que la villa no disponía de otros propios que los montes para la leña y corta de madera, los

\footnotetext{
15 Ibidem.

${ }^{16}$ Ibidem, 31 de mayo de 1679.
} 
vecinos de San Martín pedían al rey que se les liberara, durante el tiempo que continuara allí instalada la fábrica, de los repartimientos de cuarenta fanegas de trigo que tenían que entregar para la casa real y de las setenta de cebada destinadas a las caballerizas reales, puesto que en la villa no se cultivaban ninguno de los dos tipos de cereales ${ }^{17}$.

Esta petición de la villa de San Martín de Valdeiglesias fue reiterada el 13 de julio de $1680^{18}$.

La factoría siguió su actividad durante tres años más - hasta 1683y al parecer, como más adelante veremos, la gran inversión de la Real Hacienda fue poco compensatoria.

El 19 de septiembre de 1683 Lambotte acuerda traspasar la fábrica y el privilegio real, muy posiblemente por motivos de salud, a D. Antonio de Ovando ${ }^{19}$, vecino de Cadalso de los Vidrios en donde trabajaba como maestro vidriero de reconocida solvencia ${ }^{20}$. Los términos del traspaso se planteaban sobre estas sencillas bases: Lambotte le concedia el monopolio de la fábrica por los años que aún restaban por transcurrir hasta 1689 y se obligaba a manifestar a Ovando el secreto de fabricación del vidrio cristalino ${ }^{21}$. El maestro de Cadalso se comprometía por su parte a

17 AHN, Consejos, Leg. 7190. Consulta de 22 de febrero de 1680.

18 Ibidem. Consulta de 13 de julio de 1680.

19 AHN, Consejos, Leg. 7223. Consulta de 19 de septiembre de 1683.

20 D. Antonio de Ovando es citado por E. Larruga en sus Memorias al hablar de Cadalso de los Vidrios:

"Si se examina el estado de esta fábrica desde el siglo pasado (s. XVII), se nota que en el reynado de Carlos II estaba sin uso, pues don Antonio de Obando se encargó de restablecerla y de labrar vidrios y vidrieras, como lo habían hecho antes». (t. X, p. 53).

Larruga no alude al traspaso de la fábrica de San Martín de Valdeiglesias a Ovando en 1683 y sitúa cronológicamente dicho traspaso en 1692:

«...Y se encargó asimismo (Ovando) de la de San Martín de Valde-Iglesias, obligándose a pagar lo que importaban los pertrechos de ésta, en los precios y plazos que la Junta consideró justos, con diferentes condiciones y calidades que se expresan en el asiento firmado de dicho Monarca; para cuya aprobación se despachó cédula de 8 de Junio de 1692, y su cumplimiento le afianzó con escritura otorgada en 11 del mismo mes y año ante Gregorio Álvarez de Sierra". (t. X, p. 53).

Esta escritura que cita Larruga no está en el Archivo Histórico de Protocolos de Madrid.

${ }_{21}$ Entre los vidrieros era tradicional conservar el secreto de sus descubrimientos técnicos y fórmulas de fabricación, conseguidos a través de sus propias experiencias o heredados de sus mayores, secreto que ellos a su vez transmitían a sus descendientes. Lógicamente, uno de los objetivos primordiales del apoyo real a estas empresas dirigidas 
pasarle la tercera parte de sus ganancias, a las que se debería sumar una renta de tres mil ducados de pensión, concedida por el rey.

El Consejo no vio con buenos ojos el acuerdo del traspaso - pese a considerar a Ovando persona de garantía para sacar adelante la fábrica- porque Lambotte no había dejado constancia en su memorial del 10 de enero de 1679 que la fabricación del vidrio cristalino tenía una fórmula secreta que, por otra parte, no transmitió a los operarios españoles que trabajaron con él, cuando era uno de los principales cometidos hacer partícipes de sus conocimientos a los naturales del reino. En consecuencia, el Consejo juzgaba que para que el acuerdo fuera en firme, Lambotte tendría que comunicar la fórmula del vidrio cristalino no sólo a Ovando sino también a los oficiales españoles que trabajaran en la factoría, "poniendo por escrito en qué consiste el secreto y pasando a hazer experiencia de si el vidro que se labrase en la forma que Deudone Lambot espresare, es de la misma calidad que el que oy se labra, y siéndolo manifestado el secretto, V.M. podrá servirse de hacer merced de mill Ducados de renta por su vida a Deudone Lambot» ${ }^{22}$.

El 8 de octubre de 1683 muere el vidriero flamenco, según la comunicación que hacía al rey $\mathrm{D}$. Carlos de Villamayor, presidente de la Junta de Comercio y Consejero de Castilla. El propio Lambotte en su lecho de muerte participaba a éste que la fórmula secreta la conocia también su esposa Isabel Drisman, que se encargaría de traspasarla a Antonio de Ovando y a los vidrieros castellanos que trabajaban en su fábrica ${ }^{23}$.

por maestros extranjeros era que estos artífices enseñaran y formaran a los naturales, comunicándoles sus fórmulas y exhibiendo ante ellos sus habilidades.

${ }^{22}$ AHN, Consejos, Leg. 7223, 86. Consulta de 27 de septiembre de 1683.

${ }^{23}$ Villamayor, que se disponía a cumplir lo ordenado por el Consejo respecto al traspaso de la fábrica de Ovando, cuenta que "se hallaba el dicho Lambot enfermo en esta Corte y haviendo sabido que se agrababa la enfermedad, le fuy a ver para que me manifestase el secreto y no se perdiese si él faltaba, y me dijo no se perdería porque su muger le savía de la misma manera que él y cumpliría el ajustamiento hecho por Don Antonio de Obando, y porque dicho Deudone Lambot estando en este estado murió anoche, he tenido por de mi obligación dar quenta a V.M. por si tubiere en este accidente cosa nueba que mandarme de su real servicio sobre esta materia, en el interim que yo poniendo en ejecución lo resuelto por V.M. procuro que la viuda manifieste el secreto a Don Antonio de Obando y a los naturales, aunque rezelo que manifestándose y siendo común a todos, no quiera Don Antonio passar por el conzierto, pero si en esto se ofreziera dificultad que yo no pueda venzer, daré de todo quenta a V.M. para que mande lo que sea más a su servizio». AHM, Consejos, Leg. 7223, 86, consulta de 9 de octubre de 1683. 
Finalmente, el acuerdo fue ratificado en escritura pública otorgada por Antonio de Ovando y la viuda de Lambotte, a quien le fueron concedidos 1000 ducados de renta, en lugar de los 3000 que el flamenco había solicitado ${ }^{24}$. Ovando, atendiendo a la petición del Consejo, se comprometía a dejar por escrito el tantas veces mencionado secreto, para que quedara a disposición de los operarios españoles de la fábrica.

En 1684 D. ${ }^{a}$ Isabel Drisman está instalada en San Martín de Valdeiglesias compartiendo las responsabilidades del establecimiento vidriero con Ovando. En un memorial que dirige la viuda de Lambotte al rey el 26 de marzo de 1684 pide que la Justicia de la villa no la moleste más a causa de ciertas cantidades que debe, «pues en la villa están deviendo a la suplicante diferentes vecinos della muchas cantidades de maravedíes de vidrios que han sacado de su casa, sin poder conseguir con la Justicia de la dicha villa la haga pago dellas por ser la suplicante de nación extranjera. $Y$ haora subcede que por algunas cantidades mui cortas que deve, la dicha Justicia la atropella con mucho rigor, queriéndola poner presa en la cárzel, siendo como es la suplicante una muxer muy principal...» ${ }^{25}$. El 5 de abril el rey ordenaba que no se molestase durante dos meses a D. ${ }^{a}$ Isabel Drisman por razón de sus deudas ${ }^{26}$.

A través de estas noticias podemos deducir que la fábrica debió sufrir una seria crisis a partir de la muerte de Lambotte. Está documentado, por otra parte, que la gestión de éste durante los tres años que estuvo dirigiéndola no fue del agrado del rey por incumplimiento de algunos puntos del compromiso ${ }^{27}$. Todavía en 1686 continuaba el horno de San Martín de Valdeiglesias en funcionamiento, como se pone de manifiesto en la petición que hacía el Consejo a la Junta de Comercio sobre la necesidad de llevar a cabo una investigación para averiguar si Ovando había cumplido, después de hacerse cargo de él, con lo acordado en la escritura de traspaso respecto al secreto del vidrio cristalino ${ }^{28}$.

24 Ibidem, 20 de octubre de 1683.

25 AHN, Consejos, Leg. 7223, 75, 26 de marzo de 1684.

${ }^{26}$ Ibidem, 5 de abril de 1684.

${ }^{27}$ En varios documentos que se irán viendo más adelante se habla de que Lambotte no cumplió con lo que habia acordado con el rey. En consecuencia, el Consejo encarga una investigación a la Junta sobre la gestión del vidriero flamenco al frente de la fábrica de San Martín de Valdeiglesias: AHN, Consejos, Leg. 7223, 75, 12 de noviembre de 1684.

${ }^{28}$ Ibidem, 40, 12 de abril de 1686. 
En 1684 entra en escena un nuevo personaje en relación muy directa con estos acontecimientos: Santiago Bartholito (forma castellana de Giacomo Bertoletti), vidriero veneciano, muy posiblemente establecido en Flandes al salir de su patria, que fue el principal oficial que vino con Lambotte a Madrid en 1679, a quien se le encargaría la misión de continuar y completar la labor de éste. En una consulta de 12 de noviembre de 1684 se dice textualmente:

«Haviéndose visto una y otra conssultas, pareçe al Conssejo se deve adelantar todo lo possible la fábrica de vidrio christalino y que siendo Santiago Bartholito tan perito como se repressenta, deve la piedad de $V$. Magestad mandarle dar alguna ayuda de costa para que pueda permanecer en estos Reynos manifestando (como se ofreçe) su abilidad a los naturales, porque se experimente más copioso el fruto desta maniobra y por este medio çesse totalmente la entrada de los vidrios de Venecia» ${ }^{29}$.

Efectivamente, Bartholito fue propuesto por D. Cristóbal de Ontañón, solicitador fiscal de las fábricas de vidrio y papel, como principal maestro para otro establecimiento vidriero con producción al estilo de Venecia que habría de cumplir los objetivos que la fábrica de Lambotte no había cubierto. Esta propuesta está documentada el 14 de julio de 1685 y va acompañada del resumen de un memorial de Bartholito, así como de la resolución de la Junta de Comercio sobre la solicitud. La nueva fábrica que proponía Ontañón, que sería instalada en Galapagar, con el maestro veneciano al frente, tendría un costo menos elevado que la de Lambotte y habría de reportar un beneficio indudable. Bartholito se comprometía a manifestar y enseñar sus técnicas y fórmulas secretas a los naturales y a manufacturar «toda clase de vidrios y vidrieras de quantos tamaños se usan». El nuevo establecimiento colaboraría de forma notable al fomento de la industria castellana, pues gracias a él se ahorrarían las cuantiosas sumas de dinero que los venecianos obtenían con la venta de sus productos, quienes habían vuelto a intensificar su actividad comercial en los reinos de Castilla al tener conocimiento de la muerte del maestro de Flandes ${ }^{30}$.

La Junta de Comercio puso como condición, antes de aceptar la propuesta de Cristóbal de Ontañón, que Bartholito presentara unas mues-

${ }^{29} \mathrm{Ibidem}, 75,12$ de noviembre de 1684

30 AHN, Consejos, Leg. 7198, 14 de julio de 1685. 
tras de su arte para demostrar que sus habilidades eran ciertas. Se desplazó éste para ejecutar dichas pruebas a la provincia de Cuenca, concretamente a los lugares de Recuenco, Arbeteta y Alcantud, en la Serrania, en donde se concentraba la fabricación de vidrio de mediana calidad, pues la zona reunía condiciones favorables para ello. A D. Carlos Ramírez de Arellano, corregidor de Cuenca, le fue encomendada esta gestión, pero las obligaciones de su cargo le impidieron acompañar al vidriero por los lugares referidos, labor que delegó en una persona de su confianza. Bartholito tuvo que prolongar su estancia en la zona más tiempo de lo previsto ante la necesidad de tener que conseguir fuera de allí algunos materiales necesarios para su experimentación. La animosidad de los artífices locales hacia el veneciano fue la nota más destacada de su permanencia en la serranía de Cuenca. Transcribimos el fragmento del documento en el que se recogen estos hechos:

“(...) $Y$ lo mal recivido que fue este Artífice de aquellos naturales, pues con la emulación o embidia de que les quitaría con su nueva fábrica la ganancia que ellos tenían en las suyas, dando contraria inteligencia al intento que se llevava [...], le malearon de forma los morteros que había dispuesto que no pudo sacar con la perfección que requería muestra alguna de las que hizo... ${ }^{31}$.

Al volver da la corte se vieron en la Junta de Comercio las muestras que con tantas dificultades pudo al fin realizar en Recuenco y fueron admitidas como válidas, resolviéndose que «aunque en esta proposición como en las demás que se hazen y discurren para nuevas Fábricas se encuentra luego con la imposibilidad de executarlo por la falta de medios que en todas partes se experimenta y ser efectivos los que para qualquiera se necesitan, todavía considerando que ésta del Vidrio Christalino no se presupone de gran costa (aunque exceda algo del abanze que Don Cristóbal Ontañón dize ha hecho para ella), siendo tan útil como pondera y que no tiene duda que si sale tal resarcirá bien la combeniencia que rinde el gasto que tenga en execución, pareze a la Junta que si V. Magestad fuere servido, se trate della cómo y dónde Don Christóbal lo propone; mande $\mathrm{V}$. Magesiad que disponga planta y pliego en toda forma, expresando en él las cailidades y condiciones con que se ha de executar y previniendo qué obligaciones ha de hazer Santiago Bartholito

31 Ibidem. 
para cumplir lo que offreciere como Maestro de la fábrica y en particular para la enseñanza en ella de los naturales de estos Reynos, que es la mayor y más importante combeniencia que se puede tener y lo más que a él se le puede pedir quando en el pelaxe de su persona se reconoce que ni en ellos ni en otra parte alguna tiene resguardo que dar (...) ${ }^{32}$.

Finalmente, proponía la Junta que hasta que se pusiera en marcha la nueva fábrica se adjudicaran seis reales de renta diaria a Bartholito y a un oficial catalán, recomendado por Ontañón por su excelente preparación profesional para trabajar también en el establecimiento, con el fin de facilitarles un sustento e impedir que se marcharan a Mataró, en donde se les reclamaba como técnicos vidrieros.

En marzo de 1686 todavía no estaba la fábrica de Galapagar abierta, pues S. Bartholito pedía en un memorial que se empezaran los trabajos del horno de vidrio en la zona prevista (Galapagar), tras haberse interrumpido los preparativos previos a su apertura por enfermedad de Ontañón. Solicitaba, asimismo, una ayuda de costa, ya que se le estaba pagando muy mal la que se le había concedido tiempo atrás ${ }^{33}$.

Tres años después de esta última referencia a la fábrica de Galapagar, están documentadas en el Archivio di Stato de Venecia noticias relativas a un horno de vidrio en tierras castellanas que es, con toda probabilidad, el que la Junta de Comercio apoyaba a instancias de Don Cristóbal de Ontañón.

Del 11 de mayo de 1689 es una carta dirigida al embajador veneciano en España, Gio Pesaro, sin firma - probablemente de algún colaborador a quien se le habia encargado que hiciese indagaciones sobre una fábrica de vidrio veneciano que se había instalado en las cercanías de Madrid-, en la que contaba los resultados de sus pesquisas.

32 Ibidem.

33 Ibidem, 2 de marzo de 1686. En este documento se vuelve a recordar que la gestión de Lambotte había dejado problemas financieros por resolver:

«...De que para recuerdo vuelve a las Reales manos de V. Magestad la copia inclusa como también de la que zita el 3 de julio de 1684 sobre las dependencias de Deudone Lambot con todos los papeles que menciona y pertenecían a la obligación que hizo y no cumplió con los demás que después de su fallecimiento havía ocurrido tocante a introducir y establecer en estos Reynos las Fábricas de Vidrio Christalino". 
Transcribimos su contenido por ser de especial interés para este trabajo:

"La diligencia que V.C. se sirvió encargarme en relación con la nueva fábrica de Cristales introducida en Castilla, o sea de toda clase de vidrios al uso de Venecia, puedo decir a V.C. que se está construyendo el horno a cinco leguas de la corte, en el lugar llamado la Torre del Marqués; ahora se está trabajando allí para componer las cosas necesarias, conducir leña y reunir materiales. Sin embargo, hasta el día presente no se ha encendido todavía el horno ni se ha hecho un solo vaso para ver cómo resulta, aunque se ha prometido a su Magestad que se fabricarán vidrios de todas las clases, planchas para ventanas, así como espejos cristalinos y pulidos para coches. Guglielmo Toreata es el principal con el nombre de "Flamenco", aunque es natural francés de la Baja Navarra: recibirá cinco mil piezas de a ocho, dejando la mitad en ayuda de costa para los gastos del edificio, y las otras a condición de hacer frente a las facturas que pudiese necesitar la Casa Real. Tuvo el citado Toreata un horno semejante en Aragón ${ }^{34}$, pero fue traspasado aquel tráfico por falta de oficiales expertos en el oficio. El maestro que hoy está alli [se refiere al horno castellano] es natural veneciano, evadido con bando capital de la Patria y desde hace diez años está aquí, donde se ha casado, su nombre es Giacomo Bertoletti.

La situación del susodicho lugar de la Torre cae por la zona donde el Rey suele ir a cazar; en cuanto al posible éxito de tal fábrica no se deben hacer conjeturas, sino esperar a ver los resultados. Yo creo que el proponente no cumplirá con las promesas hechas a Su Magestad de producir toda la demanda que necesita esta corte, ya que se usan todas las hechuras (o modos de hacer) de Venecia, como más detalladamente se lee en el papel impreso que remití a V.C., siendo el borrador en el cual hice las anotaciones que me fueron requeridas (...). Mi parecer es que no conseguirá el proponente llevar a buen término su empeño, como muy pronto lo dirá el tiempo (...) ${ }^{35}$.

Esta versión de los hechos relacionados con la fábrica de Bartholito nos proporciona un punto de vista muy distinto del que recogen los documentos españoles. La correspondencia de los embajadores venecianos en Madrid con los "Inquisitori di Stato" es una fuente muy rica en datos

${ }^{34}$ ¿Podría referirse el embajador de Venecia a Vista Bella de Aragón, lugar que cita J. Danis como centro de fabricación de cristal? ( $v$. cita $n .{ }^{\circ} 13$ ).

${ }_{35}$ Archivio di Stato di Venezia, Inquisitori di Stato, Dispacci di Ambasciatori in Spagna (1639-1689), n. 485 . Copia de una carta existente en Madrid dirigida al embajador Gio Pesaro: 11 de mayo de 1689. En el texto figura la traducción del original italiano. 
sobre estas fábricas dirigidas por vidrieros evadidos de la República de Venecia y establecidos en tierras españolas. Los embajadores de la Serenísima tenían el encargo de seguir de cerca la actuación de estos artesanos en tierras de España y recavar información sobre los nuevos hornos que se abrieran, con el fin de controlar la competencia que podían sufrir las manufacturas de Murano que tanto éxito tenían en los reinos de España. Por su parte, las autoridades de Venecia vigilaban celosamente, con claros afanes proteccionistas, a los operarios del vidrio y prohibían con leyes muy severas su evasión fuera de las fronteras de la República, a pesar de lo cual fueron muchos los que salieron, reclamados por las distintas cortes europeas o guiados por la esperanza de hacer fortuna en el extranjero.

La fábrica que se cita en este documento es con un gran margen de probabilidad la que se estaba proyectando en Galapagar desde 1684. Santiago Bartholito es la castellanización de Giacomo Bertoletti, del manuscrito italiano (vino a España con Lambotte en 1679, y en este documento, fechado en 1689, se afirma que llevaba diez años en nuestro país). El lugar de la Torre del Marqués puede coincidir con Galapagar o sus entornos, que también distaba cinco leguas, más o menos, de la corte y por su vecindad con El Escorial era zona reservada para cacerías reales ${ }^{36}$.

El nuevo maestro que se cita aquí, Guillermo Toreata o Torcata, de origen francés, que había trabajado anteriormente en un horno de producción veneciana en Aragón, debió ser contratado para esta fábrica después del vidriero de Venecia, pues su nombre no aparece en los documentos de los años 1684-1686.

En otra carta posterior del embajador Gio Pesaro a los «inquisitori di Stato", en donde da información sobre una importante fábrica de vidrio veneciano en Lisboa, concretamente en Avrantes, incluye un párrafo final relativo al horno castellano, en el que dice que aunque se ha dado a conocer recientemente su existencia, hace ya mucho tiempo que se estaba gestionando su apertura y que está promovido con el dinero real ${ }^{37}$.

${ }^{36}$ En una consulta de 25 de abril de 1680 (AHN, Consejos, Leg. 7190), se pide al rey que exima a la villa de Galapagar de ciertos pagos que debe a cambio de los daños que sus vecinos sufren en los sembrados y zonas de cultivo por la caza mayor de los reales bosques de El Escorial.

37 Archivio di Stato di Venezia, Inquisitori di Stato, Dispacci di Ambasciatori in Spagna (1639-1689), n. ${ }^{\circ} 485,12$ de mayo de 1689. 
El 9 de agosto de este mismo año se despacha un real decreto por el que se concede a Guillermo Forcada (sin duda el mismo Guglielmo Toreata de la carta citada), "a cuyo cargo está la fábrica de vidrios", un privilegio "para el uso de ella y de las de los demás géneros de vidros", en los mismos términos (prerrogativas, exenciones, etc.) que se le concedieron a Dieudonné Lambotte ${ }^{38}$. El lugar en donde está instalada la fábrica no se cita en el documento, pero se refiere sin duda al mismo establecimiento que se cita en el Archivo de Venecia.

La última noticia relativa a la fábrica de que disponemos nos la proporciona el propio embajador veneciano, Gio Pesaro, en una carta del 18 de agosto de 1689 a los «Inquisitori di Stato», en donde dice:

«En cuanto al otro horno establecido aquí a poca distancia de Madrid, no parece que tenga la misma fortuna [que el de Avrantes en Lisboa], pues se cree que ha sido un falso montaje para obtener dinero algunos, fabricando unos cuantos vidrios con materia recocida de fragmentos de vidrios venidos de allí, por lo que no se cree que siga adelante» ${ }^{39}$.

LLama la atención que sólo nueve días después de conceder el rey a Guillermo Forcada o Toreata el privilegio, recibiera el embajador veneciano información respecto al fracaso de la factoría o posible fraude por parte de los encargados del establecimiento.

Finalmente, es importante aludir a lo que recoge Larruga en sus Memorias en relación con estos hechos.

Tanto Giacomo Bertoletti como Guglielmo Toreata son citados por dicho autor. Al vidriero veneciano se refiere al hablar del horno de San Martín de Valdeiglesias:

"Mientras vivió su Director Diodonet Lambot fue bien esta manufactura. Después tuvo por maestro a Santiago Bantoleto. Era diestro en la composición del horno y la masa, pero tenía poca habilidad para el

${ }^{38}$ AHN, Consejos, Leg. 7223, n. ${ }^{\circ} 40,2$ de agosto de 1689.

39 Archivio di Stato di Venezia, Inquisitori di Stato, Dispacci di Ambasciatori in Spagna (1639-1689), n. ${ }^{\circ} 485,18$ de agosto de 1689. 
vaceado y demás maniobras. Así los cristales salieron imperfectos y decayó la fábrica. De estos vidrios hubo almacén en la calle Mayor, donde se vendió por mayor y menor. Se nombró por superintendente de ella a Don Carlos Ramírez de Arellano".

Y continúa:

«lgualmente se estableció otra por el mismo en la Torre de Esteban Hambroz: el maestro fue Guillermo Torcada y los cuatro meses que estuvo por tal, todo el vidrio fino que salió se resquebrajaba. Perdió mucho caudal Don Francisco Laguiola su establecedor, encargó después el manejo a un catalán que lo labraba mejor, pero no como se requería. Así fue preciso a los emprendedores cargarse de deudas. De éstas resultaron embargos y procesos, y su ruina total acaeció en 1692. Los vidrios y pertrechos se vendieron en Madrid» ${ }^{40}$.

Estas noticias que recoge Larruga son imprecisas y no resuelven ninguna duda en relación con estos establecimientos vidrieros. Según el historiador y economista español, que no sitúa cronológicamente los hechos, el horno de San Martín de Valdeiglesias continuó activo después de la muerte de Lambotte (1683) con el vidriero veneciano Bartoletti o Bartholito (Bantoleto para Larruga), pero decayó por haber perdido calidad.

Esta versión no coincide con la documentación de la Junta de Comercio, pues, como se ha visto, Bartolitho gestionó, a través de Cristóbal de Ontañón, la apertura de un nuevo horno en otro lugar, ya que el de San Martín de Valdeiglesias había quedado en manos de D. Antonio de Ovando.

Respecto al segundo párrafo de Larruga podría coincidir con los datos que hemos relacionado anteriormente, pero el lugar de la Torre de Esteban Hambrán (en la provincia de Toledo) dista de Madrid casi cincuenta $\mathrm{Km}$ y la Torre del Marqués sólo unos treinta, lo que imposibilita la identificación de ambos lugares.

${ }^{40}$ E. Larruga y Boneta, Memorias..., t. XVII, p. 94. 